\title{
Clinical, hematological, biochemical, and ultrasonographic aspects of Platynosomum sp. (Trematoda: Dicrocoeliidae) infection of captive Callithrix penicillata
}

\author{
Mariana Portugal Mattioli ${ }^{1} \cdot$ Juliana dos Santos Batista $^{1} \cdot$ Marlon Ferrari $^{2}$. \\ Giane Regina Paludo ${ }^{3}$ Cecília Azevedo Dias ${ }^{4}$ Estevam G. L. Hoppe ${ }^{5}$. \\ Gino Chaves da Rocha $^{3} \cdot$ Rafael Veríssimo Monteiro ${ }^{3,6}$
}

Received: 7 July 2015/ Accepted: 5 February 2016/Published online: 27 February 2016

(C) Japan Monkey Centre and Springer Japan 2016

\begin{abstract}
Trematodes from the genus Platynosomum have been found to infect Neotropical primates in captivity, but little is known about their pathogeny in such hosts. This study evaluated the physiological effects of natural infection by the liver-dwelling trematode Platynosomum sp. in ten males and ten females of Callithrix penicillata kept in captivity at the Primate Center of the University of Brasília. The marmosets were examined twice, 6 months apart. The following parameters were analyzed: complete blood count, bleeding time, serum total protein, albumin, and the liver enzymes AST and ALT, and both a stool analysis and a liver ultrasonic evaluation were performed. We were able to characterize a group of abnormalities associated with this trematode infection which were mainly derived from the hepatitis caused by it: coagulation disorders, abnormal red blood cells, hypoalbuminemia, and abnormal levels of liver-linked serum enzymes. Eosinophilia and thrombocytopenia were
\end{abstract}

Rafael Veríssimo Monteiro

rvmonteiro@unb.br

1 Hospital Veterinário, Faculdade de Agronomia e Medicina Veterinária, Universidade de Brasília, Brasília, DF, Brazil

2 Serviço de Ultrassonografia, Hospital Veterinário, Faculdade de Agronomia e Medicina Veterinária, Universidade de Brasília, Brasília, DF, Brazil

3 Faculdade de Agronomia e Medicina Veterinária, Universidade de Brasília, Brasília, DF, Brazil

4 Centro de Primatologia, Universidade de Brasília, Brasília, DF, Brazil

5 Faculdade de Medicina Veterinária, UNESP Jaboticabal, Jaboticabal, SP, Brazil

6 Hospital Veterinário, Faculdade de Agronomia e Medicina Veterinária, Universidade de Brasília, Av. L4 Norte/Asa Norte, Brasília, DF 70910-900, Brazil also commonly seen. All of the aforementioned abnormalities were in good accord with typical effects of trematodes on liver parenchyma. We suggest that this set of abnormalities is characteristic of the infection of $C$. penicillata with Platynosomum sp., and should be among the most prominent aspects that the veterinary surgeon considers when suspecting such an infection. We also suggest that these clinical signs and abnormalities will be similar in other liver-dwelling trematode-infected primate species.

Keywords Black-tufted marmoset · Health rank - Liver disease $\cdot$ Hepatic ultrasound $\cdot$ Trematode hepatopathy

\section{Introduction}

Breeding groups of captive neotropical primates are commonly maintained in large cages or open enclosures to promote a social structure closer to natural conditions, thereby enhancing welfare and the reproductive success of the colony. However, the more natural the enclosure, the greater the risk of exposure of the housed primate to undesirable external parasites. These parasites may harm the primate, causing diseases ranging from low-impact illnesses which are easily treated and controlled to severe clinical impairments which may even result in death. In any case, the primate may develop physiological abnormalities significant enough to preclude it from being used as an experimental subject. Reproductive impairment is another common consequence of disease, and one that is also detrimental to colony viability. Therefore, the spread of external parasites in a primate colony may cause medical and reproductive problems, not to mention the economic losses incurred due to the significant investment involved in housing each animal in such research facilities. 
The Centro de Primatologia da UnB (CPUnB) is a Brazilian primate research center which houses neotropical species, mainly capuchin monkeys (Sapajus apella), blacktufted marmosets (Callithrix penicillata), and squirrel monkeys (Saimiri sciureus). The CPUnB is located inside the Brasília University experimental farm in a well-conserved Cerrado area (Brazilian savanna), away from any agricultural activities. Wild populations of $C$. penicillata and Alouatta caraya also roam free over the farm's Cerrado conservation area. This location permits very calm, nature-integrated enclosures, but it also allows parasites to reach the captive monkeys. Wild-borne parasitic disease may arise from two commonly observed situations: (1) invertebrates and small vertebrates - potential intermediate hosts or carriers of many parasites - enter the cages and are eaten by captive primates; (2) wild, free-roaming primates interact with those in captivity.

At the end of 2006, liver-dwelling trematode parasites were identified during the necropsies of two deceased marmosets. From 2006 to 2012, marmosets died from abnormalities which were tentatively linked to trematode infection. Based on a comparison of the specimens collected from necropsied marmosets with descriptions provided by Kingston and Cosgrove (1967) and Travassos et al. (1969), the parasite was identified as Platynosomum sp. (Fig. 1). Little is known about trematodes that infect nonhuman primates, but they are commonly found in the pancreas, gall bladder, and biliary ducts (Toft 1982; Sousa et al. 2008). Light infestations are mostly asymptomatic, but high burdens cause thickening of the biliary ducts and traumatic compression of the surrounding tissue, resulting in hepatic cell degeneration and vacuolization (Marcos et al. 2008; Rojo-Vázquez et al. 2012). The histological modifications caused by Platynosomum sp. in the liver of a congeneric primate species, $C$. jacchus, were shown to be portal fibrosis, ascending cholangitis, cholestasis, and even secondary biliary cirrhosis (Sousa et al. 2008). Infections with this trematode genus currently pose a problem for other primate centers throughout Brazil (Sousa et al. 2008; Silva et al. 2012).

Hepatic disease may be characterized clinically and by laboratory tests. Clinical signs such as jaundice and an enlarged and palpable liver are typical. These signs are correlated with high serum levels of the liver-associated enzymes AST and ALT (Tygstrup 1990; Marcos et al. 2008). Liver disease may cause other clinical signs, such as coagulation disorder and edema, both of which are related to impairment of coagulation cascade precursors and albumin synthesis (Kavanagh et al. 2011). Ultrasounds and other image-based exams may also be performed in order to evaluate liver abnormality, severity, and localization. This research aimed to analyze clinical signs, blood counts,

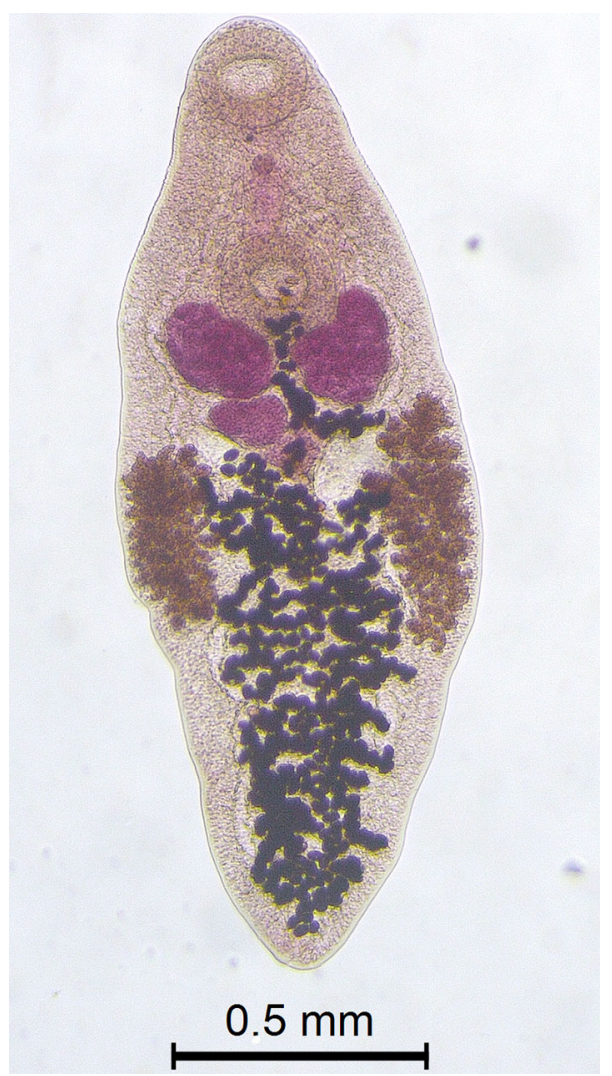

Fig. 1 Specimen of Platynosomum sp. collected from the liver of a dead marmoset from the CPUnB. Authorship: G.C. Rocha

biochemical profiles, and liver ultrasound images of blacktufted marmosets infected by Platynosomum sp.

\section{Methods}

\section{Human care guidelines}

All of the procedures described below were approved by the Ethical Committee for the Use of Animals of UnB, under the number 53242/2011. The Primatology Center granted their full consent to collect samples from the animals.

\section{Marmoset characteristics and restraint technique}

The 20 adult marmosets (ten males and ten females) of species Callithrix penicillata were housed at the CPUnB, and their body weights ranged from 245 to $410 \mathrm{~g}$ (321 g on average). The marmosets were fed with a small-primatespecific commercial chow which was supplemented daily with a mix of fruits and vegetables. Twelve of these marmosets (eight males, four females) were born at the 
CPUnB. At the time of the sampling, the youngest was 1 year and 4 months old while the oldest was 8 years and 5 months old. The other eight individuals came from zoo captivity or were provided by the governmental agency. The most recently arrived had spent 6 months at the $\mathrm{CPUnB}$, and the longest housed marmoset was there for a year and a month. Except for the trematode infection, no other helminths were characterized in flotation and sedimentation stool examination techniques. Moreover, no other parasites or infections were characterized in the necropsies routinely performed on dead marmosets from the CPUnB-whether they were based on macroscopic examinations or histological slides-that could be associated with hepatic disease.

During the year before our first sample, the twenty marmosets were submitted to $12-15$ stool examinations in blocks of three successive days of stool collection. All marmosets provided at least one trematode-positive stool sample; 14 of them had four or more positive stool samples. The marmosets had been deverminated on two occasions during this previous year with praziquantel, $150 \mathrm{mg} / \mathrm{kg}$, PO, SID or nitazoxanide, $150 \mathrm{mg} / \mathrm{kg}$, PO, BID, with both drugs administered on three successive days. All marmosets were trematode-free at least once after devermination. This recursive trematode infection cycle is putatively attributed to the constant reinfection of marmosets after the ingestion of unidentified invertebrate intermediate hosts originating from outside the cages.

Two samples were taken 6 months apart (these two samplings are referred to in the text below as "S1" and "S2"). Two females were pregnant and so no blood samples were taken from them at $\mathrm{S} 1$, resulting in a total of 38 blood samples. The same deworming schedule described above for nitazoxanide was repeated between the two samplings. The frequency of occurrence of Platynosomum sp. in the marmoset stools ranged from $90 \%$ at S1 to $35 \%$ at S2. Leather gloves and nets were used during sampling to briefly restrain all individuals in order to facilitate the intramuscular administration of a combination of $20 \mathrm{mg} / \mathrm{kg}$ of ketamine (Cetamin, Syntec, Brazil) and $1 \mathrm{mg} / \mathrm{kg}$ xylazine (Calmium, Agener Uniao, Brazil) (Joslin 2003). While unconscious, each subject was weighed, and its body temperature $\left({ }^{\circ} \mathrm{C}\right)$ as well as their cardiac and respiratory frequencies were monitored at 5-min intervals throughout the trans-anesthetic period.

\section{Blood collection}

Peripheral blood was collected from the femoral-inguinal vein with a $3-\mathrm{mL}$ syringe attached to a $20 \mathrm{~mm} \times 0.6 \mathrm{~mm}$ needle (PrecisionGlide, BD, Brazil). The blood was divided into two vials: a dry one which allowed the blood to clot for serum separation, and another containing sodium heparin (Hemofol, Cristalia Ltda, Brazil) as an anticoagulant to enable a blood count.

\section{Health parameter analysis}

\section{Bleeding time evaluation}

The bleeding time (BT) after blood collection was used as an indirect measure of the primary hemostasis of the marmosets. Subjects with no sign of bleeding $3 \mathrm{~min}$ after venipuncture were classified as having good primary hemostasis. Any bleeding after this time classified the animal as having delayed primary hemostasis. The proportion of marmosets with a delayed bleeding time was compared to the expected distribution (10\% of the animals would present this abnormality) through a chi-square test, considering an alpha of 0.05 .

\section{Blood analysis}

Red and white blood cells (RBCs and WBCs, respectively), together with thrombocytes (Thromb), were counted using the classical protocol with a Neubauer chamber. Hematocrit (HT) was determined by centrifugation of blood-filled capillary tubes at $13000 \mathrm{rcf}$ for $5 \mathrm{~min}$ (Celm MH, Celm, Brazil). Leukocyte types were counted in blood smears stained with rapid panoptic stain (Instant Prov, NewProv, Brazil). Blood hemoglobin (HB) content was determined by spectrophotometry. The mean cell hemoglobin concentration (MCHC), mean cell hemoglobin $(\mathrm{MCH})$, and mean cell volume (MCV) were calculated from the aforementioned values. The following serum enzymes and proteins were evaluated using spectrophotometry: AST, ALT, total protein (TP), and albumin (ALB). These analyzes were conducted with commercial kits (Labtest, Brazil) and a semi-automatic spectrophotometer (BIO 2000, BIOPLUS, Brazil).

\section{Statistical evaluation of the Platynosomum sp. infection pattern}

We used two different approaches to evaluate the Platynosomum sp. infection pattern in our marmoset sample. First, we compared the mean health parameter values of our trematode-infected marmosets with the corresponding values reported by Yarbrough et al. (1984). The mean point between the adult male and female values as displayed in Yarbrough et al. (1984) was considered for the average and standard deviation calculations. We compared the mean values of the two studies using a $t$ test considering an alpha level of 0.05 . We looked for significant differences which would indicate a general effect of trematode infection on the marmoset population. 
Second, to identify common characteristics of the most severely trematode-sick animals, we compared the value of each health parameter for each trematode-infected marmoset with a reference range also created based on Yarbrough et al. (1984). The reference range corresponded to the average plus or minus two standard deviations. We counted the number of marmoset individuals above or below the established limits (of the reference range) for each health parameter. We employed a chi-square test (alpha $=0.05)$ to investigate any statistical difference from the expected distribution of 5, 90, and $5 \%$ of the primates with values below, within, and above the reference range, respectively.

Finally, using a $t$ test $(p<0.05)$, we compared the mean health parameter values of the trematode-positive (23 individuals, 18 from $\mathrm{S} 1$ ) to those of the trematode-negative (15 individuals, 13 from S2) marmosets in order to characterize which parameter values were significantly modified after the worms had been removed from the marmosets. All tests were performed with the software R.

\section{Ranking marmosets by health}

A health rank (HR) was obtained for each animal sampled based on the results of the clinical and laboratory examinations. The residual $z$ score for each parameter was calculated for each animal. Our health rank was derived from the sum of the $z$ scores, as shown below:

$$
\begin{aligned}
& \mathrm{HR}=\text { zscore }(\mathrm{HT}+\mathrm{RBC}+\mathrm{HB}+\mathrm{ALB})-\text { zscore }(\mathrm{BT} \\
&+\mathrm{WBC}+\mathrm{EOS}+\mathrm{AST}+\mathrm{ALT})
\end{aligned}
$$

We used the HR for two purposes. First, we evaluated how many marmosets were at the lower $2.5 \%$ limit of the HR, and which characteristics they had in common. Second, we compared the HR values at $\mathrm{S} 1$ to those at S2. One standard deviation of the HR was used to define reference thresholds that could be used to identify the animals that showed an improvement or a deterioration in health at the second sampling.

\section{Hepatic ultrasonography}

The ultrasound examinations (US-E) were conducted with a MyLab 30 VET ultrasound machine (Universal Ultrasound, USA) wired to a $12-\mathrm{MHz}$ linear probe. All examinations $(n=39)$ were performed by a single investigator (M. Ferrari). One marmoset from S1 was not submitted to US-E. The animals were restrained in dorsal recumbency and the fur over the abdominal area was completely shaved. A generous amount of ultrasound gel was applied over the area to be scanned. The best liver images obtained were utilized to describe the shape and size of the liver and the echotexture and echogenicity of the liver parenchyma and gall bladder. The gall bladder was analyzed in terms of its contour, relative size, wall thickness, and content. The distance from the liver to the sternum (DLS; in $\mathrm{cm}$ ) was compared between animals considered to have normal livers and those considered to have hepatitis or both hepatitis and hepatomegaly using a one-way ANOVA; significance was set at $p<0.05$.

\section{Results}

\section{Bleeding time}

Table 1 presents the observed and expected distributions of marmosets with normal or delayed bleeding times. The proportion of animals that presented problems with primary hemostasis was significantly higher than expected at both $\mathrm{S} 1$ and $\mathrm{S} 2$.

\section{Effects of Platynosomum sp. infection on overall population health}

Table 2 shows that some of the parameters were statistically different from their reference means. The trematodeinfected marmoset population presented higher hematocrits because of higher RBC counts, but had lower mean cell hemoglobin concentrations and albumin serum levels. The leukocyte profile for the marmoset population indicates that they have significantly lower mean neutrophils, eosinophils, lymphocytes, and thrombocytes than the corresponding reference means.

\section{Marmosets with out-of-range health parameter values}

Table 3 shows that Platynosomum sp. infection modified black-tufted marmoset health parameters to the point that many of them could be considered unhealthy. The

Table 1 Classification of a group of twenty black-tufted marmosets based on bleeding time at two different sampling sessions S1 and S2

\begin{tabular}{llcc}
\hline Sampling season & \multicolumn{2}{l}{ Bleeding time status } & $p$ \\
\cline { 2 - 3 } & Normal & Delayed & \\
\hline S1 & 12 & 6 & 0.03 \\
S2 & 15 & 5 & 0.03 \\
Expected distribution & $16 / 18^{\mathrm{a}}$ & 2 & \\
Total & 27 & 11 & 0.03 \\
Expected distribution & 34 & 4 & \\
\hline
\end{tabular}

Expected frequencies were calculated based on the assumption that $90 \%$ of the marmosets would have normal bleeding times and $10 \%$ would have delayed bleeding times. Observed frequencies were compared to the expected ones using a chi-square test. Samplings were performed 6 months apart

${ }^{\text {a }}$ Expected frequencies for S1 and S2, respectively 
Table 2 A $t$ test comparison of the mean health parameter values obtained in this work with those reported by Yarbrough (1984)

\begin{tabular}{|c|c|c|c|c|}
\hline \multirow[t]{2}{*}{ Health parameter } & \multirow[t]{2}{*}{$n$} & \multirow{2}{*}{$\begin{array}{l}\text { This research } \\
\text { Mean (SD) }\end{array}$} & \multicolumn{2}{|l|}{ From Yarbrough (1984) } \\
\hline & & & Reference mean (SD) & $95 \%$ Reference range \\
\hline \multicolumn{5}{|l|}{ Blood analysis } \\
\hline $\mathrm{HT}(\%) * *$ & 38 & $48(5)$ & $42(8)$ & $26-58$ \\
\hline $\mathrm{HB}(\mathrm{g} / \mathrm{dL})$ & 34 & $14.2(2.6)$ & $15.6(2.7)$ & $10.2-21.0$ \\
\hline $\mathrm{RBC}\left(\times 10^{6} / \mathrm{mL}\right)$ & 38 & $5.5(1.8)$ & $5.7(1.1)$ & $3.5-7.9$ \\
\hline $\mathrm{MCV}(\mathrm{fL}) * *$ & 38 & $94(30)$ & $73(5)$ & $63-83$ \\
\hline $\mathrm{MCH}(\mathrm{pg})$ & 34 & $28(11)$ & $27.5(4)$ & $19.5-35.5$ \\
\hline $\operatorname{MCHC}(\%)^{* *}$ & 34 & $29.9(4.4)$ & $38(4.7)$ & $28.6-47.4$ \\
\hline WBC $\left(\times 10^{3} / \mathrm{mL}\right)$ & 38 & $8.5(5.4)$ & $7.8(3.0)$ & $1.8-13.8$ \\
\hline Neutrophils $(/ \mathrm{mL})^{*}$ & 38 & $5196(3960)$ & $3822(1248)$ & $1326-6318$ \\
\hline Band cells $(/ \mathrm{mL})^{* *}$ & 38 & $400(371)$ & $23(69)$ & $0-161$ \\
\hline Eosinophils $(/ \mathrm{mL})^{* *}$ & 38 & $321(429)$ & $39(78)$ & $0-195$ \\
\hline Basophils (/mL) & 38 & $77(24)$ & $94(133)$ & $0-360$ \\
\hline Lymphocytes $(/ \mathrm{mL})^{*}$ & 38 & $2667(2130)$ & $3588(1170)$ & $1248-5928$ \\
\hline Monocytes (/mL) & 38 & $412(478)$ & $273(226)$ & $0-725$ \\
\hline Thrombocytes $\left(\times 10^{3} / \mathrm{mL}\right) * *$ & 25 & $144(104)$ & $281(111)$ & $59-503$ \\
\hline \multicolumn{5}{|l|}{ Serum biochemistry } \\
\hline Total protein $(\mathrm{g} / \mathrm{dL})$ & 35 & $6.6(1.5)$ & $6.9(0.8)$ & $5.3-8.5$ \\
\hline Albumin $(\mathrm{g} / \mathrm{dL})^{* *}$ & 38 & $3.4(0.6)$ & $4.8(0.7)$ & $3.4-6.2$ \\
\hline AST (U/L) & 35 & $119(94)$ & $149(44)$ & $61-237$ \\
\hline ALT (U/L) & 36 & 52 (107) & $55(20)$ & $15-95$ \\
\hline
\end{tabular}

$S D$ standard deviation

$* p<0.05$;* $p<0.01$

modifications occurred to four groups of parameters: (a) red blood cell size and hemoglobin content characteristics; (b) leukocyte profile; (c) serum albumin levels; and (d) levels of serum proteins that are dependent on liver metabolism.

\section{Modifications to health parameter values after deworming}

Table 4 presents the health parameters for which the trematode-positive marmosets (mostly at S1) and trematode-negative marmosets (mostly at S2) presented statistically significantly different values. We consider these differences to indicate the parameters that improved the most after the marmosets were dewormed.

\section{Health rank analysis}

The average HR of the 38 animals was $-0.29 \pm 4.79$ (mean $\pm \mathrm{SD}$ ) and the rank distribution was skewed towards the worst ranks (skew $=-0.68$ ). One animal had an HR $(-15.11)$ that was below the lower limit $(2.5 \%)$ of the reference range (-9.87). This marmoset was one of the pregnant females in $\mathrm{S} 1$. The other female pregnant at $\mathrm{S} 1$ also had a very low HR $(-9.53)$ at S2.
When comparing the 18 individual HRs at S1 and S2 (excluding the two females that were not sampled at S1), we noticed that the health of two marmosets (one male, one female) had deteriorated, but only the male was Platynosomum sp.-negative in the stool exam. The aforementioned female showed the most pronounced health deterioration, with an HR reduction of 8.41 units. Five marmosets showed health improvements (one male, four females), with three animals becoming free of trematode infection. The aforementioned male marmoset displayed the best health improvement between the two sampling sessions, as its HR rose by 10.39 units. The HRs of the other animals fluctuated within the $1 \mathrm{SD}$ limit. The HR did not differ statistically significantly depending on stool exam status.

\section{Liver ultrasonographic characteristics during trematode infection}

US-E of the livers that were considered normal showed the usual appearance: preserved organ margins and size together with a hypoechoic homogeneous echotexture. The biliary bladder may have been be filled with anechoic homogeneous bile and may have had a hyperechoic wall. In contrast, the liver images that were considered characteristic of inflammatory hepatitis ( $49 \%$ of the marmosets) 
Table 3 Number of lack-tufted marmosets that were infected with Platynosomum sp. and had health parameter values that were outside the corresponding reference ranges

\begin{tabular}{|c|c|c|c|c|}
\hline \multirow[t]{2}{*}{ Health parameter } & \multirow[t]{2}{*}{$n$} & \multicolumn{3}{|c|}{ Frequency of individuals with out-of-range values } \\
\hline & & Below & Above & $p$ value \\
\hline \multicolumn{5}{|l|}{ Blood analysis } \\
\hline HT (\%) & 23 & 0 & 0 & \\
\hline $\mathrm{HB}(\mathrm{g} / \mathrm{dL})$ & 21 & 1 & 0 & \\
\hline $\mathrm{RBC}\left(\times 10^{6} / \mathrm{mL}\right)$ & 23 & $5^{*}$ & 2 & $<0.001$ \\
\hline MCV (fl) & 23 & 2 & $13 *$ & $<0.001$ \\
\hline $\mathrm{MCH}(\mathrm{pg})$ & 21 & 3 & $4^{*}$ & $<0.005$ \\
\hline $\mathrm{MCHC}(\%)$ & 21 & $12 *$ & 0 & $<0.001$ \\
\hline $\mathrm{WBC}\left(\times 10^{3} / \mathrm{mL}\right)$ & 23 & 2 & 1 & \\
\hline Neutrophils $\left(\times 10^{3} / \mathrm{mL}\right)$ & 23 & 2 & $5^{*}$ & $<0.001$ \\
\hline Band cells $\left(\times 10^{3} / \mathrm{mL}\right)$ & 23 & 0 & 1 & \\
\hline Eosinophils $\left(\times 10^{3} / \mathrm{mL}\right)$ & 23 & 0 & $6^{*}$ & $<0.001$ \\
\hline Basophils $\left(\times 10^{3} / \mathrm{mL}\right)$ & 23 & 0 & 0 & \\
\hline Lymphocytes $\left(\times 10^{3} / \mathrm{mL}\right)$ & 23 & $9 *$ & 0 & $<0.001$ \\
\hline Monocytes $\left(\times 10^{3} / \mathrm{mL}\right)$ & 23 & 0 & 3 & \\
\hline Thrombocytes $\left(\times 10^{3} / \mathrm{mL}\right)$ & 18 & $5^{*}$ & 0 & $<0.001$ \\
\hline \multicolumn{5}{|l|}{ Serum biochemistry } \\
\hline Total protein $(\mathrm{g} / \mathrm{dL})$ & 20 & 2 & 1 & \\
\hline Albumin $(\mathrm{g} / \mathrm{dL})$ & 21 & $9 *$ & 0 & $<0.001$ \\
\hline AST (U/L) & 21 & $4 *$ & 2 & $<0.01$ \\
\hline ALT (U/L) & 22 & $6 *$ & $5^{*}$ & $<0.001$ \\
\hline
\end{tabular}

Expected frequencies for chi-square calculations were $5 \%$ of marmosets below the lower limit of the reference range, $90 \%$ between the upper and lower limits of the reference range, and $5 \%$ above the upper limit. The number of marmosets that were within the reference range is not shown for the sake of clarity. The reference ranges used are shown in Table 2, and were calculated based on the average plus or minus two standard deviations as presented by Yarbrough (1984)

* Statistically significant deviation from the expected value

\begin{tabular}{llcl}
\hline Health parameter & \multicolumn{2}{l}{ Platynosomum sp. infection status } & $p$ \\
\cline { 2 - 4 } & Positive & Negative & \\
\hline WBC $\times 10^{3} / \mathrm{mL}$ & 6.56 & 11.57 & 0.004 \\
Neutrophils $\times 10^{3} / \mathrm{mL}^{-1}$ & 3.91 & 7.17 & 0.011 \\
Lymphocytes $\times 10^{3} / \mathrm{mL}^{-1}$ & 2.11 & 3.53 & 0.040 \\
\hline
\end{tabular}

Table 4 Health parameters for which the trematode-positive and -negative marmosets presented statistically significantly different values after deworming the parasitological results for the stool, as $42 \%(8 / 15)$ of the trematode-negative marmosets presented it.

\section{Discussion}

The results presented in this work indicate a Platynosomum sp. infection pattern in the Callithrix penicillata individuals sampled, which is compatible with its parasitic mode of action. The typical pathogenesis of liverdwelling trematodes results from their invasion of the liver and the establishment of parasitic cysts which affect the bile ducts and surrounding tissue (Marcos et al. 2008; Rojo-Vázquez et al. 2012). Liver cell death 
Fig. 2 Liver ultrasonographic image for a black-tufted marmoset; the image shows the granular aspect characteristic of inflammatory hepatitis.

Ultrasound performed by $\mathrm{M}$. Ferrari

Fig. 3 Abnormalities found in the liver ultrasonographic image of a black-tufted marmoset (Callithrix penicillata) infected with Platynosomum sp. $\mathrm{CH}$ hepatic parasitic cysts, $F i$ liver parenchyma fibrosis spots, $P E$ thickened gall bladder wall, $G B$ gall bladder. Ultrasound performed by M. Ferrari
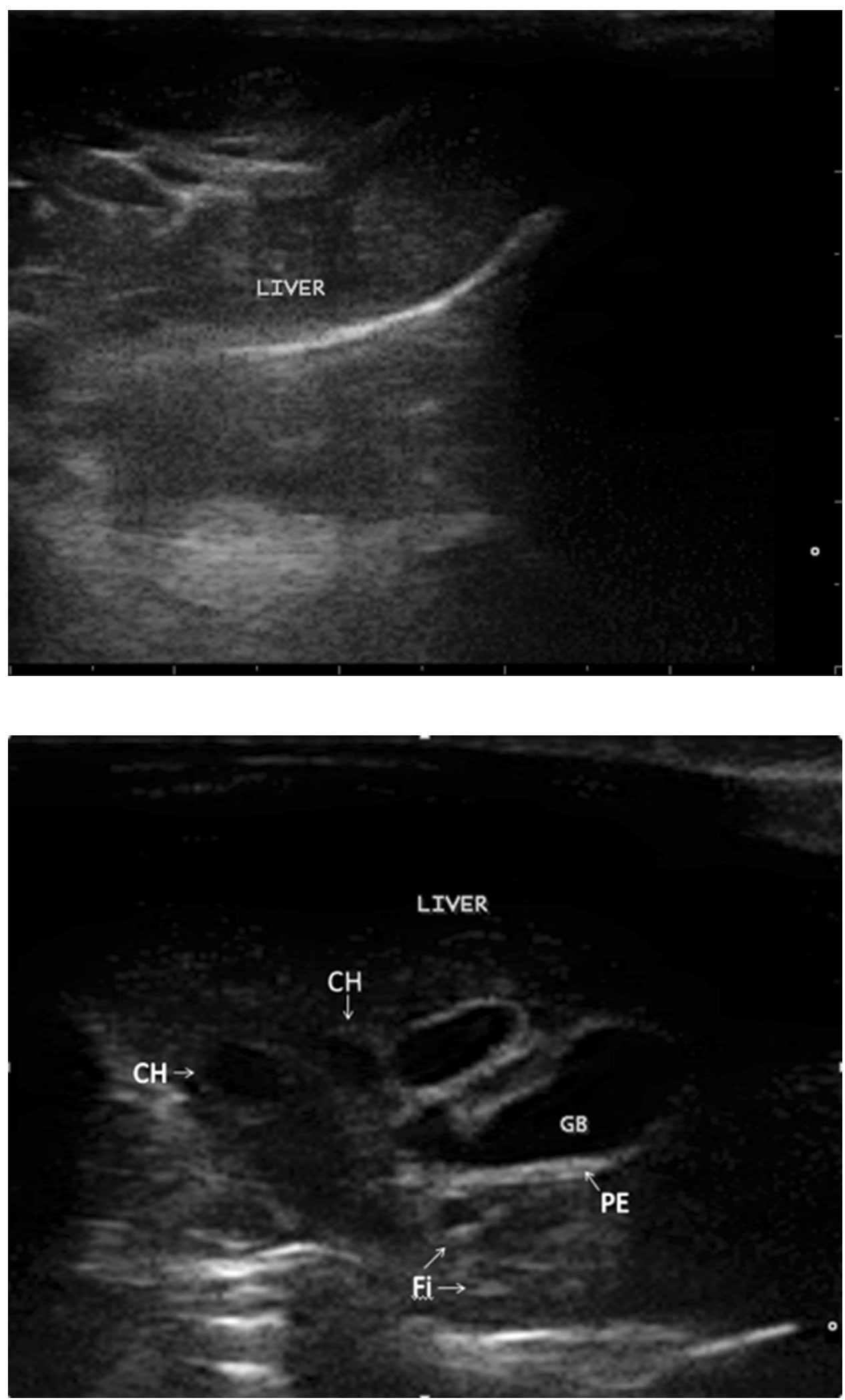

leads to fibrosis and liver enlargement, or even a reduction in size in severely ill animals (Sousa et al. 2008). All of these effects impair liver function, potentially causing primate death when the trematode burden is high and the resulting liver damage is significant. In our work, Platynosomum sp. infection was 
found to compromise hepatic functions in three ways: (a) impairment of bleeding control; (b) impairment of red blood cell production; and (c) impairment of albumin synthesis.

We found that our experimental Platynosomum sp.-infected marmosets had a significantly higher frequency of delayed bleeding (Table 1). Low platelet counts were also seen not only at the population level (Table 2) but also at the individual level (Table 3). Coagulopathies are a common consequence of hepatic disease, and thrombocytopenia is characteristically found in trematode infections. Liver parenchymal cells synthesize most of the coagulation factors, while the liver's reticuloendothelial system helps to clear activation products. Local decreased platelet aggregation, disseminated intravascular coagulation, occult thrombosis, autoimmune destruction of platelets, and gastrointestinal hemorrhage may all contribute to driving the patient into a hypocoagulatory state. It is noteworthy that even in S2, when most of the marmosets were trematodefree, a high proportion of the marmosets still had bleeding abnormalities (Kavanagh et al. 2011).

The trematode-infected marmoset population of the present study, while not, on average, anemic (Table 2), had individuals with macrocytic hypochromic anemia (Table 3), a common characteristic observed in the pathogeny of other liver-dwelling trematodes (Valero et al. 2008). This morphologic classification is consistent with a regenerative anemia, reflecting the increased size and decreased hemoglobin of the reticulocytes (Barger 2003). This anemia may have multiple causes. The blood-sucking trematodes (which cause hemolysis) provoke increased hematopoiesis turnover, meaning that insufficient RBCs many be produced due to progressive hepatic destruction and low iron storage. The proline released during trematode metabolism also induces anemia in rat fasciolosis (Spengler and Isseroff 1981; Coffin et al. 1984). Extrapolating from the proposed classification of Valero et al. (2008) for trematode-associated anemia, all of our marmosets were in the early to advanced chronic phases of infection.

The hypoalbuminemia demonstrated by the data shown in Tables 2 and 3 is commonly associated with peripheral or generalized edema, which was not diagnosed in our experimental marmosets. This does not mean that these clinical signs could not appear afterwards, with liver deterioration and prolongation of the disease. In this case, we cannot rule out the possible appearance of other clinical signs linked to hypoalbuminemia, such as fur loss, dyspnea, muscle weakness, and/or wasting (Tygstrup 1990).

Hepatic parenchyma abnormalities can also be inferred by evaluating the typical liver-associated enzymes AST and ALT. Among our trematode-infected marmosets, some displayed high serum levels of AST and ALT, signaling recent hepatic damage (Table 3). Other marmosets which displayed lower-than-normal AST and ALT levels were probably animals with a prior chronic infection that led to a cirrhotic, diminished liver. It is interesting to note that the average values of these two health parameters did not differ from their respective reference values. This was because both excessively high and excessively low values were observed in this work, meaning that the liver enzyme averages did not shift markedly from the reference values. Population health analysis should always consider the extreme values and the data distribution.

Table 2 also indicates that trematode infection modified the leukocyte profiles of the infected hosts. On average, these marmosets displayed neutrophilia, lymphopenia, and eosinophilia; some individuals also displayed leukocytosis. This is a typical leukocyte profile for hosts infected with trematodes (Marcos et al. 2008; Robinson and Dalton 2009). Table 3 reiterates this profile, showing more individuals than expected in the extreme reference range for these WBC types. Chronic inflammation, such as the hepatitis observed in these marmosets, in conjunction with a stress response (Barger 2003) mediated by glucocorticoid released during manual restraint of the marmosets, may account for this profile. We also noticed that the dewormed marmosets presented significantly increased neutrophil and lymphocyte counts (Table 4). Immunosuppression is a possible outcome of hepatic disease. Another hypothesis is that it could be a shift of leukocytes from the liver parenchyma to the systemic circulation following deworming. Regardless of the explanation, an improved immune response can be expected from dewormed marmosets.

Our health rank analysis showed that, overall, the marmoset population affected by Platynosomum sp. was diseased, but some animals were in worse health than others, making these individuals more likely to die. The two females that were pregnant at the first sampling had very low HRs in the second sampling. This highlights that the combination of a compromised liver and the physiological demands of pregnancy will compromise female health and may result in death. We believe that this may well also be the case for other physiologically demanding activities, such as growth and the immune response. In these cases, marmoset health may be impaired, potentially reducing growth rates and weakening the immune response of the marmoset to parasites.

US-E confirmed that invasion of the hepatic parenchyma by Platynosomum sp. results in inflammatory hepatitis and parasitic cyst development, and may lead to hepatomegaly. The different DLSs of marmosets with different hepatic parenchyma inflammatory statuses is an expression of this inflammation. However, given that nearly all of our marmosets were infected at some point during the experimental period, we consider that the presence (or absence) of these 
abnormalities is dependent on the parasite burden and the timing and length of trematode infection for each marmoset. The histopathological modifications that were previously observed in $C$. penicillata infected by Platynosomum sp. (Sousa et al. 2008) are in good accord with the US-E images obtained for the trematode-infected marmosets in the present study.

Comparison of the health ranks at S1 and S2 showed that removing the trematode infection marks the beginning of recovery. The veterinary clinician should expect liver function impairment to last longer than the infection due to the liver fibrosis resulting from infection, which will persist for the rest of the marmoset's life. Veterinarians should consider this when contemplating the marmoset's feed and general care needs, as well as eventual therapeutics.

Many of the abnormalities observed in the trematodeinfected marmosets studied here (anemia, neutrophilia, lymphopenia, eosinophilia, increased or decreased AST and ALT, and hepatomegalia) are also seen in cats infected with P. fastosum (Basu and Charles 2014). As also occurs with cats, marmosets may forage on cercariae-infected molluscs and isopods, as well as small lizards. In a free-range situation, such marmosets would be unlikely to encounter and ingest cercariae-infected intermediate hosts because they are much more likely to feed on other insects and even other types of food. However, with captive marmosets, a local cycle can establish. Invertebrates feed inside the enclosures on the trematode-infected marmoset feces, and marmosets eat these new intermediate hosts of Platynosomum sp. This positive feedback may lead to a large proportion of the potential invertebrate intermediate hosts in the enclosure becoming infected with Platynosomum sp. cercariae, causing a high reinfection rate in the marmosets, as seen in the CPUnB.

Finally, we suggest that our clinical examination panel can be used to diagnose Platynosomum sp. infection in black-tufted marmosets, and that this panel should also work in other primate species and for other liver-dwelling trematodes. Also, the health rank we used is able to identify which of the infected marmoset individuals were in the worst condition, and this method is replicable in other animal models. Marmosets with a low health status should be more intensively treated and cared for. Health rank may thus act as a red flag for animals with particularly pronounced impairment of physiological function.
Acknowledgments Mariana P. Mattioli and Juliana dos S. Batista were supported by the PIBIC program of UnB.

\section{Compliance with ethical standards}

Conflict of interest The authors declare that they have no conflict of interest.

\section{References}

Barger AM (2003) The complete blood cell count: a powerful diagnostic tool. Vet Clin North Am Small Anim Pract 33:1207-1222

Basu AK, Charles RA (2014) A review of the cat liver fluke Platynosomum fastosum Kossack, 1910 (Trematoda: Dicrocoeliidae). Vet Parasit 200:1-7

Coffin JD, McGarry MP, Isseroff H (1984) Proline induced hemolytic anemia in fascioliasis. Proc Soc Exp Biol Med 177:92-96

Joslin JO (2003) Other primates excluding great apes. In: Fowler ME, Miller RE (eds) Zoo and wild animal medicine. Saunders, St. Louis, pp 346-381

Kavanagh C, Shaw S, Webster CR (2011) Coagulation in hepatobiliary disease. J Vet Emerg Crit Care (San Antonio) 21:589-604

Kingston N, Cosgrove GE (1967) Two new species of Platynosomum (Trematoda: Dicrocoeliidae) from South American monkeys. Proc Helminth Soc Washington 34:147-151

Marcos LA, Terashima A, Gotuzzo E (2008) Update on hepatobiliary flukes: fascioliasis, opisthorchiasis and clonorchiasis. Curr Opin Infect Dis 21:523-530

Robinson MW, Dalton JP (2009) Zoonotic helminth infections with particular emphasis on fasciolosis and other trematodiases. Philos Trans R Soc B 364:2763-2776

Rojo-Vázquez FA, Meana A, Valcárcel F, Martínez-Valladares M (2012) Update on trematode infections in sheep. Vet Parasitol 189:15-38

Silva KS, Silva RJ, Pereira WL (2012) Occurrence of infection by Platynosomum illiciens (Braun, 1901) in captive neotropical primates. Primates 53:79-82

Sousa MB, Leão AC, Coutinho JF, de Oliveira Ramos AM (2008) Histopathology findings in common marmosets (Callithrix jacchus Linnaeus, 1758) with chronic weight loss associated with bile tract obstruction by infestation with Platynosomum (Loos, 1907. Primates 49:283-287

Spengler RN, Isseroff HJ (1981) Fascioliasis: is the anemia caused by hematophagia? J Parasitol 67:886-892

Toft JD II (1982) The pathoparasitology of the alimentary tract and pancreas of nonhuman primates: a review. Vet Pathol Suppl 7:44-92

Travassos L, Freitas JFT, Kohn A (1969) Trematódeos do Brasil. Mem Inst Oswaldo Cruz 67:1-886

Tygstrup N (1990) Assessment of liver function: principles and practice. J Gastroenterol Hepatol 5:468-482

Valero MA, Gironès N, García-Bodelón MA, Periago MV, ChicoCalero I, Khoubbane M, Fresno M, Mas-Coma S (2008) Anaemia in advanced chronic fasciolosis. Acta Trop 108:35-43

Yarbrough LW, Tollett JL, Montrey RD, Beattie RJ (1984) Serum biochemical, hematological and body measurement data for common marmosets (Callithrix jacchus jacchus). Lab Anim Sci $34: 276-280$ 